\title{
0 gênero fantástico e a ficção como ponte em La VISTA DESDE EL PuENTE, de Ramiro Sanchiz
}

\author{
Eulálio Marques Borges \\ Juan Pablo Chiappara
}

\begin{abstract}
Resumo
Este trabalho apresenta os resultados de uma pesquisa de Iniciação Científica realizada no Departamento de Letras da Universidade Federal de Viçosa, Minas Gerais, e foca uma discussão sobre o romance uruguaio contemporâneo La vista desde el puente, de Ramiro Sanchiz. Neste artigo propomos uma leitura contextualizada no processo de renovação da literatura uruguaia, que busca romper com a tradição predominantemente realista no Uruguai. Deste modo, postulamos que a literatura fantástica, tal como a propõe Sanchiz e outros escritores uruguaios, engloba a ficção científica e se distancia de certas formas de não realismo precedentes dentro da América Latina. No caso concreto do romance analisado, Sanchiz desconstrói a figura mítica do herói nacional uruguaio Artigas e a ideia do Uruguai como a Suíça da América e propõe uma ficção que dialoga com a tradição borgeana de fantástico para desconstruir certos clichês da história nacional e das práticas literárias mais frequentadas em seu país.
\end{abstract}

Palavras-chave: desconstrução; história uruguaia; literatura fantástica.

\section{Resumen}

Este trabajo presenta los resultados de una investigación de Iniciación Científica realizada en el Departamento de Letras de la Universidad Federal de Viçosa, Minas Gerais, y enfoca una discusión sobre la novela uruguaya contemporánea La vista desde el puente, de Ramiro Sanchiz. En este artículo proponemos una lectura contextualizada en el proceso de renovación de la literatura uruguaya, la cual busca romper con la tradición predominantemente realista en Uruguay. De este modo, postulamos que la literatura fantástica, tal como la propone Sanchiz y otros escritores uruguayos, engloba la ficción científica y se distancia de ciertas formas de no realismo precedentes dentro de América Latina. En el caso concreto de la novela analizada, Sanchiz desconstruye la figura mítica del héroe nacional uruguayo Artigas y la idea de Uruguay como Suiza de América y propone una ficción que dialoga con la tradición borgeana de lo fantástico para desconstruir ciertos clichés de la historia nacional y de las prácticas literarias más frecuentadas en su país.

Palabras clave: desconstrucción; historia uruguaya; literatura fantástica. 


\section{INTRODUÇÃO}

La vista desde el puente (SANCHIZ, 2011) é um romance que se encaixa em um contexto de produção literária pós-crise sofrida pelo Uruguai no início do século XXI, quando jovens escritores, repensando os fundamentos sobre os quais se erguia o país e a literatura nele produzida, acentuaram o distanciamento temático e estilístico com as narrativas passadas, algo que já vinha acontecendo através de gerações anteriores, e começaram a escrever obras de cunho fantástico, que se opõem ao cânone estabelecido por autores cujas ficções estão voltadas para o realismo e preocupadas com o compromisso social, como é o caso de Mario Benedetti e Eduardo Galeano. O maior desafio dessa nova fase é construir um público receptor de sua literatura e vencer os interesses locais dominantes estabelecidos no campo literário, sempre mais voltados para o mencionado estilo realista, que para esta geração de começos do século XXI, que desafia o stato quo dominante no Uruguai.

Em La vista desde el puente Sanchiz narra-se a viagem de Federico Stahl, seu protagonista, à cidade de Corrientes, aqui pertencente ao território uruguaio mas que, em realidade, forma parte da atual Argentina. A viagem realizada por esse Uruguai expandido funciona como pano de fundo para que o autor do romance construa uma sociedade correntina indígena que, ainda no século XXI, sofre com a perseguição de um grupo racial suprematista que contou, em seu passado, com a participação de José Artigas, considerado pela historiografia oficial uruguaia o herói responsável pela independência do país. Entretanto, o território fictício que encontramos no livro não serve apenas para desconstruir figuras nacionais modeladas ao longo de mais de um século, mas também para o desenvolvimento do gênero fantástico dentro da narrativa, que neste artigo trabalharemos melhor.

$\mathrm{O}$ presente artigo tem como ponto de partida a leitura de alguns textos com os quais dialoga e a partir dos quais se estrutura. Em primeiro lugar, um artigo científico sobre o romance La vista desde el puente que o analisa desde a perspectiva da identidade multiterritorial (MONTOYA JUÁREZ, 2013). Ademais, parte-se da análise de alguns textos que abordam o atual panorama literário uruguaio por meio da perspectiva da geração pós-ditadura; ditos textos comentam o espaço dado ao fantástico e à ficção científica dentro da literatura uruguaia e evidenciam a luta de alguns autores nas últimas décadas pela preservação destes gêneros em meio a uma sociedade mais acostumada a obras realistas (SANCHIZ, 2008; SANCHIZ, 2009; SANCHIZ, 2010; SANCHIZ, 2011a; SANCHIZ 2011b; SANCHIZ 2012). Além desses diálogos, é fundamental para nós um artigo de Julio Prieto sobre a formação do gênero fantástico na América Latina (PRIETO, 2009), assim como um artigo que relata a construção idílica da figura política de Artigas, personagem chave dentro da trama do romance analisado. (DELGADO, 2014).

É a partir desse material de base que apresentamos, primeiramente, a atual situação da literatura uruguaia, colocando-a em perspectiva com o conceito de literatura fantástica em 
língua espanhola criado por Borges e Bioy na década de 1940 e, em um segundo momento, realizamos uma análise de como o gênero fantástico aparece em La vista desde el puente. Nosso objetivo final é mostrar como Sanchiz desafia o status quo intelectual e político uruguaio ao transformar sujeitos históricos do país em personagens não idealizados dentro de uma sociedade distópica onde uma ponte não apenas física, mas principalmente social e cultural, separa os dois polos do país, Montevidéu e Corrientes; desconstruindo, assim, a figura mítica do herói nacional José Gervasio Artigas e, portanto, de uma sociedade que persiste em endeusá-lo como o herói laico de uma república que custa a se renovar do ponto de vista do imaginário, Sanchiz oferece um romance pseudo-histórico que é antes de mais nada um exercício de literatura fantástica que homenageia o gênero.

\section{A literatura uruguaia atual vista por Ramiro Sanchiz}

Nascido em 1978, Ramiro Sanchiz publica muitos de seus textos em seu próprio blog, Aparatos de vuelo rasante bem como em outros meios virtuais. Em uma de suas publicações, Sanchiz (2012) analisa o contexto editorial contemporâneo no Uruguai, beneficiado nos últimos anos pelo investimento público em forma de subvenções e prêmios e pelo surgimento de editoras como HUM e Estuario. Ambas difundem obras de autores menos conhecidos e são as responsáveis para que escritores como Mario Levrero seja relido e revalorizado pela comunidade local. Essa nova realidade literária uruguaia, onde autores publicam com mais facilidade que antigamente, leva Gabriel Lagos (2009) a realizar um estudo que divide essa nova geração em três grupos: os pop, mais claros e objetivos em sua escrita, os intimistas, que dão um grande valor à primeira pessoa e escrevem obras entre a autobiografia e a autoficção, e os sérios, preocupados com as teses e com o formal do texto.

Entretanto, ao analisar de forma menos sistemática e mais crítica a geração póscrise por meio de três antologias que surgiram em 2008 (El descontento y la promesa, Esto no es una antología e De acá), ano considerado de fundamental importância para esse novo grupo justamente por conta das compilações que aí surgiram, Sanchiz (2012) afirma que nenhum desses livros que reuniram contos de escritores uruguaios representou, de fato, uma mudança significativa para a literatura do país. Com relação ao primeiro dos três, organizado por Hugo Achugar, Sanchiz afirma que foi realizado apenas um agrupamento de vozes dentro de um compartimento etário não capaz de divulgar novos talentos que de fato rompessem com uma literatura mais tradicional. Esta afirmação se apoia no texto inicial de El descontento y la promesa, escrito pelo próprio Achugar, que afirma que um dos critérios no momento de selecionar os escritores do seu livro foi o fato de terem nascido como máximo em 1973, pois esses fariam parte de uma geração que cresceu durante a transição entre o regime ditatorial e a abertura democrática, o que consequentemente os influenciou ao momento de produzir suas obras. Como afirma Achugar: "Una historia que los interpela como ciudadanos, pero que no 
necesariamente los convoca como artistas, al menos no en la mayoría de los casos." (ACHUGAR, 2008, p.18). Ainda que possam parecer totalmente inovadores por conta da ruptura com a literatura política e social, a maior novidade desses jovens artistas se limita justamente a isso, já que seguem reconhecendo seus antecedentes por meio de intertextualidades, dialogismos e sem mudar a ideia hegemônica de narrativa. No fragmento abaixo, vemos melhor a opinião de Achugar (2008) quanto à nova geração.

Sin embargo, como es sabido, "no hay nada nuevo bajo el sol" y el escenario contemporáneo, incluso en esta fase de recomposición cultural o de mutación civilizatoria, mantiene diálogos con escenarios y prácticas del pasado al mismo tiempo que elabora escenarios futuros difícilmente imaginables desde el presente de este hoy en que escribo (ACHUGAR, 2008, p.14)

Já a segunda mostra das três, Esto no es uma antología, é criticada pelo autor de La vista desde el puente devido à falta de proposta definida e sua pouca divulgação por pertencer a uma série de livros produzidos pelo Ministerio de Relaciones Exteriores e a Universidad del Trabajo e possuir um circuito mais diplomático que popular, não tendo sido distribuída em livrarias ou divulgada pela crítica especializada por meio de resenhas. A última delas, De acá!, ainda segundo Sanchiz, por mais que seja a compilação mais combativa de todas, falha devido ao tom forçosamente engraçado que imprime nas auto apresentações de seus autores, como vemos melhor explicado nesse fragmento:

La pretensión de diferenciarse de los "pruritos académicos" de Achugar y de los "desgastados recursos magritteanos" de Bernardo, lamentablemente (y digo "lamentablemente" porque si algo hacía falta en este panorama de muestras de narrativa era la actitud combativa propia de los escritores del under, el tipo de prologuista que, alucinado, convencido y/o convincente sale a defender a los autores que incluyó con un cuchillo entre los dientes y los ojos cuarteados en sangre), produjo la muestra más endeble de las tres. El tono canchero o de vuelta que satura las palabras de apertura parece encontrar su reflejo en la sencilla boludez de las presentaciones. (SANCHIZ, 2012, p.6)

Além das compilações mencionadas, Sanchiz (2012) analisa também os livros 22 mujeres, Entíntalo e Sobrenatural, lançados no ano de 2012. Enquanto o primeiro é considerado o mais pop de todos, o segundo surgiu através de um concurso de jovens narradores, não significando um rompimento com a tradição realista uruguaia, e o terceiro é visto por Sanchiz como decepcionante ao retratar o gênero fantástico e/ou a fantasia em seus contos pois falha justamente no desenvolvimento dos códigos da narrativa fantástica, mostrando-se apegado à literatura tradicional visível no cânone literário do país (SANCHIZ, 2012). Assim sendo, a pergunta final que ele realiza após sua análise é simples e direta: "El "nuevo canon” propuesto 
por algunas editoriales - HUM en particular -, con Polleri, Lissardi, Echavarren y Espinosa a la cabeza, ¿implica una verdadera renovación?" (SANCHIZ, 2012, p.5). Respondendo seu próprio questionamento, ele afirma que Uruguai nem sequer possui, em sua opinião, uma tradição literária, no sentido de não existir, segundo ele, uma série de escritores que possam ser vistos num fluxo de continuidade e diálogo ao longo da vida republicana, e que por isso os novos autores não conseguiram rompê-la da maneira como esperavam, aceitando uma tradição que vende mais no mercado editorial e desfazendo, por fim, a promessa de uma renovação. Com essa pequena contextualização do cenário no qual se insere a nova geração literária uruguaia e de sua produção, abordaremos brevemente a história do gênero fantástico em língua espanhola e sua definição, que dialoga com o principal objeto de nosso trabalho, La vista desde el puente, livro que rompe com o tradicionalismo literário vigente no Uruguai.

\section{A literatura fantástica em líNgUa espanhola}

A partir da década de 1940, Jorge Luis Borges e Bioy Casares realizaram um trabalho teórico em que se dedicaram a construir uma nova concepção de literatura fantástica em língua espanhola. Essa nova ideia do que é o fantástico buscava retirar o gênero da marginalidade por meio da progressiva eliminação do sobrenatural, característica que consideravam inferior às demais, àquelas naturais ou que indicavam alucinação (PRIETO, 2009).

Bioy Casares e Borges, junto a Silvina Ocampo, organizam a Antología de la literatura fantástica (1940), obra que reúne diversos contos fantásticos da antiguidade ao século XX e de diversas origens culturais, em espanhol. Visando esclarecer os pressupostos dessa compilação, encontramos no prólogo do livro uma breve história do gênero e uma maior atenção dada ao fato de que o ambiente fantasmagórico e sinistro sempre foi o caminho mais comum seguido pelos autores dessa literatura que, com o tempo, deixou de despertar a surpresa necessária para chamar a atenção de seus leitores. Assim, afim de mostrar a existência de outras maneiras de se trabalhar uma trama fantástica, os autores dessa antologia reuniram nela apenas dois contos onde aparecem fantasmas, dando maior atenção à tramas com fantasias metafísicas e viagens ao tempo, por exemplo.

Em meio aos argumentos que defendem essa nova visão do fantástico, encontramos também a menção de Borges, no prólogo de La invención de Morel (1997) sobre a principal "falha" cometida pelas novelas "psicológicas", que de acordo com ele, desejam ser tão realistas e informativas que terminam por tornar-se inaceitáveis como criações fictícias, enquanto a novela de aventuras, primeiro nome dado às obras fantásticas, se caracteriza justamente pelo contrário da anterior, ou seja, por ser um objeto artificial que não se preocupa em parecer real. Para respaldar sua argumentação e mencionar um livro por ele considerado fantástico, mas não sobrenatural, Borges (1997) toma como exemplo La invención de Morel (1940), de Bioy Casares, quem de acordo com ele "Despliega una odisea de prodigios que no parecen admitir otra clave 
que la alucinación o que el símbolo, y plenamente los descifra mediante un solo postulado fantástico pero no sobrenatural.” (BORGES, 1997, p.161).

Assim, de acordo com Prieto (2009), a frase "Fantástica, pero no sobrenatural", presente tanto no prólogo de Antología de la literatura fantástica quanto no "Prólogo" de La invención de Morel, ambos escritos originalmente em 1940, ainda que pareça incongruente, principalmente para a época em que foi divulgada, resume o princípio desse projeto. Ou seja, com a ideia de violar o sentido comum de literatura fantástica existente naquela época, Borges e Bioy tinham como objetivo reconstruir a noção desse gênero em língua espanhola e colocálo em um lugar privilegiado, onde se encaixavam os romances realistas, como afirmado por Prieto (2009) no fragmento abaixo:

La conspicua repetición de la misma frase en ambos textos sugiere que, lejos de ser una coincidencia, un ánimo programático emana esas proposiciones: se trataría de perturbar las inercias y convenciones de un género, de desarraigar los protocolos de sentido de un término que en el siglo anterior vagaba por las brumas de los géneros menores, de removerlo y trasplantarlo a otras latitudes. (PRIETO, 2009, p.57-58)

Esta reconstrução e redefinição, que ainda nos dias de hoje suscita discussões, começou a partir do momento em que Borges e Bioy traduziram do inglês as palavras novel, referente aos relatos realistas, e romance, que se refere aos relatos não realistas. Aproveitando o espaço em branco que surgiu com o segundo término, que em espanhol significa uma família de línguas ou um tipo de composição poética, Borges e Bioy criaram sua própria definição do gênero fantástico em espanhol, como vemos melhor explicado no fragmento abaixo:

\footnotetext{
"Literatura fantástica" es el modo en que Borges y Bioy designan el vacío rellenándolo con perversa creatividad - que en nuestra lengua y en nuestra teoría literaria proyecta la oposición terminológica que en inglés permite distinguir los relatos realistas (novel) de los no realistas (romance). Es curioso observar que la casilla vacía o término "en blanco" para designar en español la literatura no realista sólo se hace visible al superponer los sistemas de categorización de las dos lenguas, como una suerte de eco dejado en el español por el inglés a partir de una perspectiva bifocal o bilingüe - es decir, justamente la perspectiva de la que parten escritores como Bioy y Borges -. (PRIETO, 2009, p.61)
}

Foi através desse "mal entendido" de um processo tradutório e da não tradição do gênero fantástico em língua espanhola que se tornou possível a renovação de algumas fórmulas estrangeiras esgotadas, surgindo, então, a definição de literatura fantástica em espanhol, que de acordo com Bioy Casares é: “(...) una suerte de cajón de sastre en que cabrían todo tipo de formas de imaginación literaria no realista, tanto modernas como premodernas (...)" (BIOY CASARES apud PRIETO, 2009, p 60). Ainda segundo Prieto (2009), esta primeira definição em castelhano seria um caso análogo ao de Edgar Allan Poe, que em seu 
livro Tales of the Grotesque and the Arabesque (1840), reflete sobre o termo fantástico, se referindo a ele por meio de palavras como grotesco e arabesco devido à conotação pejorativa que a expressão fantastic, em inglês, possuía nos Estados Unidos daquela época.

Quando propuseram retirar o sobrenatural da literatura fantástica, Borges e Bioy criaram, consequentemente, um sentido restrito ao gênero que descarta o irracional, mas que valoriza e funda uma literatura fantástica que transita entre o real e aquilo que eles entendem por fantástico. Jorge Luis Borges foi um autor que não manifestou interesse por obras inverossímeis, mas sim por uma literatura lógica, por uma verossimilhança que ocorre principalmente no imaginário dos personagens e os influencia em suas ações e pensamentos; com histórias mais subjetivas, Borges trabalha com a linha tênue existente entre a realidade e a fantasia, o que ele mesmo chamou de causalidade "mágica" (PRIETO, 2009). O romance La vista desde el puente, foco da pesquisa que originou este trabalho, é uma obra que se insere dentro de uma nebulosa conceitual por estar entre a ficção científica, o romance policial e a literatura fantástica que dialoga com a definição proposta por Borges e Bioy e que lhe interessa a seu autor, Ramiro Sanchiz. A partir das definições aqui expostas, passaremos a uma análise mais detalhada das características fantásticas dentro deste romance.

\section{O GÊNERO FANTÁSTICO EM LA VISTA DESDE EL PUENTE}

Ambientada no ano de 2006 em um Uruguai expandido sobre parte da atual Argentina, mais precisamente sobre a província de Corrientes, La vista desde el puente nos apresenta uma nação fictícia e reterritorializada, característica que de acordo com Montoya Juárez (2013) é bastante comum na literatura latino-americana atual. O contexto de múltiplos territórios e de sujeitos que por eles transitam, assim como o não compromisso em assumir-se latino-americano, ou seja, de não necessariamente identificar-se com a cultura local, de sentirse cômodo ou não ao estar nela ou de transmitir por meio da literatura a história e as características político-sociais dessa região ou de algum país a ela pertencente, se relacionam com a frase dita por Flaubert "No soy más francés que chino" (AÍNSA apud MONTOYA JUÁREZ, 2013, p.2), que pode ser comprovada por meio da Rússia vista aos olhos do cubano José Manuel Prieto nos livros Treinta días en Moscú (2001) e El tartamudo y la rusa (2002), e também pela Alemanha retratada em Oscuro bosque Oscuro (2009), do mexicano Jorge Volpi. Portanto, ao contrário do que faziam autores hispano-americanos como Mario Vargas Llosa, Eduardo Galeano e García Márquez, que se dedicavam a retratar a América Latina em suas obras, os escritores atuais já não se veem com esse compromisso e se permitem ir além do lugar em que nasceram, criando suas histórias em outros países ou reterritorializando determinada nação, como o faz Sanchiz em La vista desde el puente.

Ao narrar a viagem feita por Federico Stahl de Montevidéu a Corrientes após a misteriosa morte de seu pai, Sanchiz nos mostra um Uruguai fictício, com grande população 
indígena residente ao norte do país e polarizado em dois grandes centros, sendo o primeiro a capital tecnologicamente desenvolvida e de população majoritariamente branca, enquanto o segundo polo do país, Corrientes, é tido como um lugar pobre, atrasado e que tem como "função" concentrar o grande número de índios derrotados que ainda resta. Essa reterritorialização elaborada por Sanchiz cria a primeira das inúmeras pontes construídas pelo autor ao largo da obra, que funciona como uma espécie de máquina do tempo capaz de fazer o protagonista se sentir em uma cidade do século XIX, como vemos no trecho abaixo:

La única vez que había visitado Corrientes sintió, al bajar del ómnibus, que funcionaba allí una suerte de vórtice espaciotemporal capaz de llevarlo ciento cincuenta años al pasado. En el liceo le habían repetido hasta el cansancio que Uruguay tenía dos polos: Montevideo, que representaba las presuntas conquistas de la modernidad y la cultura europea, y Corrientes, último bastión de aquel país de indios derrotado por el avance de la Iglesia y Occidente. (SANCHIZ, 2011, p. 11)

É possível, então, inserir Sanchiz nessa tendência multiterritorial da literatura da América Latina e considerar isto como uma estratégia para pensar o tratamento dado aos indígenas que viveram no Uruguai e que, após lutarem contra os colonizadores espanhóis e portugueses, foram exterminados em 1831 pelo primeiro governo republicano do país. Entretanto, essa crítica não se aproxima em nenhum momento a uma visão romantizada em defesa da preservação da cultura indigenista; ela serve, acreditamos, a um dos seus objetivos principais: o de denunciar a verdadeira história de uma nação que se esqueceu de suas raízes e desconstruir o mito da "Suíça da América", difundido principalmente durante o século XX e que supunha a ideia de que o território uruguaio se assemelhava, em economia, cultura e qualidade de vida de sua população, a um dos países mais desenvolvidos da Europa e localizado geograficamente entre grandes potências. No fragmento que segue, vemos um pouco mais do retrato pintado por Sanchiz dessa Corrientes imaginaria que destrói a idealização do território uruguaio:

Estaba en el barrio viejo, cerca de la manzana del Cabildo y la Catedral; miró los edificios más recientes, incrustados entre la vieja piedra gris del siglo diecinueve, y sintió una vez más que toda aquella ciudad no era más que los restos fantasmales de algo, humano o bestia, que había vivido hacía demasiado tiempo, de algo que se había parado ante la tempestad y aguantado, pero que no sobrevivió al día siguiente, cuando el sol asomó entre las nubes quebradas. (SANCHIZ, 2011, p.139)

Além disso, a sensação de ter viajado no tempo, sentida pelo protagonista Federico, se encaixa no conceito de literatura fantástica difundido por Borges e Bioy durante a década de 1940. O ônibus que liga as duas grandes cidades desse país imaginado por Sanchiz funciona como uma máquina que leva o personagem principal, ao menos em sua imaginação, 
ao início da colonização uruguaia, quando tudo era precário, como ainda é a cidade da romanesca Corrientes. Ainda que seja uma situação irreal a experimentada por Federico, a existência de grandes diferenças socioculturais em um mesmo país é verossímil.

Se essa ponte construída entre Montevidéu e a fictícia Corrientes pertencente a um fictício Uruguai expõe parte das características fantásticas da obra de Sanchiz e desconstrói a ideia da "Suíça da América", outras pontes montadas ao longo da trama servem para desmistificar o legado artiguista difundido por diferentes governos uruguaios ao longo do século XX como paradigma do bem e da essência do nacional. José Gervasio Artigas foi, de acordo com Delgado (2014), um líder revolucionário que pretendia unir a Banda Oriental, como era conhecido Uruguai naquela época, com algumas províncias da atual Argentina para formar o que seria a Liga Federal (que existiu de 1815 a 1820); entretanto, após ser derrotado na Batalha de Tacuarembó, foi exilado no Paraguai, onde permaneceu até sua morte. Com o início do batllismo e a necessidade de se ter um referente nacional, o governo da época elevou sua imagem à categoria de herói nacional, movimento que chegou ao seu ápice em 1926 com a inauguração de sua estátua na Praça da Independência, em Montevidéu, e foi ratificado em 1977, com a construção de seu mausoléu, pela ditadura militar, debaixo do mesmo monumento.

A fim de desconstruir essa imagem idílica e falsa, uma vez que Artigas não foi o responsável pela independência do Uruguai, Ramiro Sanchiz constrói, junto ao já mencionado fictício território uruguaio povoado por charruas ao norte, um governo artiguista passado liderado por um José Artigas que se tornou um tirano ao longo dos anos, aliando-se a um grupo suprematista e planejando o extermínio de toda a população indígena. Além dele, o escritor Isidore Ducasse, conhecido como o Conde de Lautréamont, autor do livro Os cantos de Maldoror (1869), é colocado na obra como o primeiro serial killer uruguaio responsável pelo assassinato de inúmeros índios. Ao estabelecer essa ponte entre o real e o fantástico, Sanchiz desconstrói figuras conhecidas e respeitadas pelo establishment político, social e cultural de seu país e se mostra contra a literatura mais tradicional apegada à um realismo valorizado pelas editoras e pelo público local.

Outras pontes são estabelecidas ao longo da obra, como a que se forma e reúne novamente Federico e Rafael através da investigação sobre o "verdadeiro" Artigas. Sem um contato direto ou amigável com seu pai desde que este o abandonou para viver com a nova família em Corrientes, Federico Stahl se viu obrigado, após a morte do historiador, a conviver outra vez com sua imagem. Entretanto, a relação entre os dois era agravada precisamente pela oposição de ideias sobre o governo artiguista, pois enquanto Rafa acreditava no espírito justo do líder uruguaio, seu filho era adepto da ideia de que o caudilho se tornou um louco durante os anos em que governou Uruguai. Ainda que esta nova convivência entre os personagens se dê somente por meio dos estudos e notas que por Rafael haviam sido deixados, percebe-se 
uma aproximação entre eles também no âmbito profissional, já que a partir da pesquisa não terminada por seu pai, Federico se sente confortável para elaborar outra novela, o que já não realizava há tempos. O trecho abaixo ilustra esta ponte que se forma entre pai e filho.

\begin{abstract}
No era el momento de ponerse a escribir, por supuesto, y además no había secuencia inicial, no había primeras palabras, no había voces o personajes; pero la idea de pensar esa novela comenzó a tentarlo. No significaba renunciar al proyecto de editar el tercer tomo de la biografía, pero era fácil sentir que, si su padre realmente había pensado en ofrecerle los materiales para un libro especial, era lo mismo que pensar que el viejo había tendido un puente, que ese libro sería una suerte de colaboración paternofilial post mortem, que aquello implicaba un reencuentro, pero no en el territorio propio de su padre, la historia, sino en el del hijo, la ficción. (SANCHIZ, 2011, p.52)
\end{abstract}

Entretanto, a ponte mais complexa de toda a história, pelo menos para o seu protagonista, é a que tenta relacionar o antigo Rafael, o pai que Federico conheceu em seu passado, ao novo Rafael, o desconhecido que viveu anos em Corrientes com sua nova família, começou a descobrir a existência de um Artigas tirano durante a pesquisa que daria origem à biografia do líder, manteve em seus últimos anos de vida uma amante charrua e se matou, se é que se matou, provavelmente por não aguentar ver que o prócer que sempre defendeu era um louco insano como seu filho sempre lhe dizia. Todos estes questionamentos surgem pouco a pouco, mas adquirem maior força quando Federico visita a casa da amante de seu pai, também assassinada pelo grupo suprematista, momento descrito na seguinte passagem:

Federico quiso imaginar aquella casita en su esplendor, cuando la mujer recibía a su padre en la sala, cuando cenaban juntos, cuando cogían. ¿De qué hablaban antes y después? ¿Cómo se despedían por las noches, por las tardes o por las mañanas? Si en la casa de Estela e Isabel las huellas de su padre eran tan claras y legibles como los surcos de un disco de vinilo para la púa de tocadiscos, aquí el hombre proyectado era otro: coincidía con su padre sólo porque Viera le había informado de aquella historia y porque las llaves que abrieron la puerta de la casa estaban en el estudio del viejo; el resto era el perfil de otra persona o, al menos, un perfil todavía por descifrar. Era el comienzo de un acertijo, y se volvía necesaria, otra vez, la presencia de un puente, pero no uno roto, como los que había imaginado Federico al mirar el riachuelo, límite de Villa Paraná, sino uno que se clavase en ese nudo de tiempo y espacio que había sido su padre y lograse proyectarse hacia el enigma. (SANCHIZ, 2011, p.58)

Como afirmamos anteriormente, La vista desde el puente se encontra entre os géneros de ficção científica, policial e fantástico. Se o primeiro se comprova pela história se encontrar dentro do marco da ucronia distópica, o segundo se mostra, primeiramente, por meio dos misteriosos assassinatos charruas, todos eles relacionados à sociedade suprematista da qual Artigas e Ducasse faziam parte, mas também pelo jogo proposto já em morte por Rafael.

Em relação às características fantásticas, está claro que elas aparecem por meio do 
território imaginado por Sanchiz, na desconstrução da imagem de Artigas e de Ducasse e através também da situação charrua na cidade de Corrientes. Entretanto, quando Federico foge de seus sequestradores e consegue a ajuda de um casal indígena que vive ao redor da cidade correntina, ele passa por alguns momentos onde, pelo menos em sua cabeça, dois mundos paralelos existem, sendo um deles o que ele vive e outro, um universo que mantém a cultura indígena originaria daquela região; nesse momento, o fantástico ganha ainda mais força. A ideia de dois mundos é, na verdade, natural em livros de ficção científica, como Planeta Arreit (1976), de Horacio Terra Arocena, e podemos vê-la transcrita abaixo na obra de Sanchiz.

Federico miró las construcciones que rodeaban la feria y pensó que acaso había accedido a un universo paralelo en el que la conquista jamás había sucedido y las culturas originarias habían establecido grandes ciudades que a través de la magia y la tecnología lograban comunicarse con mundos paralelos. (SANCHIZ, 2011, p.125)

Além disso, a droga aparece em La vista desde el puente por meio de um chá, talvez a ayahuasca, que o casal indígena oferece a Federico quando o encontra ferido. É este chá que o ajuda a se recuperar e produz em sua mente a alucinação de estar em um mundo distinto, rudimentar, que se perdeu ao longo dos anos, como vemos abaixo:

Los dos indios lo miraban. Bebió de a poco el resto del té, y dejó que el sabor se acumulase, capa tras capa, sobre las superficies de su boca. Era un gusto amargo y seco, como a una corteza a la que está naciéndole un brote verde y tierno. Pero había más. Era como internarse en el sabor, como bajar una escalera peldaño a peldaño y descubrir una faceta más del ámbito al que estaba descendiendo, detalles, juegos de luz, texturas en las paredes, objetos dispersos aquí y allá. Sabor a flores, a semillas, quizá un ligero toque de algo animal, sangre, pelo, carne." (SANCHIZ, 2011, p.122)

Estes fragmentos indicam que o fantástico, na obra de Sanchiz, aparece de distintas formas, seja pela imaginação de um novo Uruguai, pela imagem reformulada de um herói nacional ou pelo consumo de drogas que causa a alucinação dos dois mundos, que no livro é, em parte, real devido à diferença social entre Montevidéu e Corrientes. O ponto comum entre essas diferentes formas de mostrar a fantasia dentro do romance é que todas servem para estabelecer uma ponte entre a história uruguaia que é contada e considerada oficial pela política do país e a recriada ficcionalmente pelo autor de La vista desde el puente.

\section{CONCLUSÃo}

Por meio da análise desenvolvida aqui, podemos concluir que Ramiro Sanchiz usa o gênero fantástico não apenas como entretenimento, mas sim como forma de romper com a 
tradição mais realista à qual não só a literatura uruguaia, mas sim a latino-americana no geral, estão acostumadas. Mais que isso, ao reconstruir a história de seu próprio país por meio de um Uruguai com problemas de perseguição étnica na verdade inexistentes, já que sua população indígena foi exterminada no início da República, Sanchiz toca justamente nessa ferida por considerar que a nação em que vive, como um todo, se espelhou no falso mito da "Suíça da América" e acabou se esquecendo de suas verdadeiras origens ou, pelo menos, "trapaceou" ao construir seus mitos civilizatórios.

A desconstrução do personagem chave dessa trama, o líder José Artigas, representa um rompimento maior com parte da historiografia uruguaia que o considerou durante o século XX, e de alguma forma ainda o considera, o verdadeiro herói da independência nacional. Pensá-lo como um tirano associado a um grupo suprematista pode ser considerado um ato de rebeldia se levamos em consideração a sociedade tradicional na qual Sanchiz está inserido. É assim que se constrói a ponte entre a verdade histórica e a verdade literária da independência uruguaia neste livro, sendo a segunda uma forma exagerada de repensar e questionar a primeira, que também contêm suas características imaginativas, não se caracterizando pela pureza dos fatos, como afirma Delgado (2014). Por fim, podemos pensar que a ficção é vista por Sanchiz como algo iniludível, ou seja, do qual não se pode escapar, fazendo-se presente e necessária no momento de compreender a história e a cultura de qualquer nação. 
1. Aparatos de vuelo rasante é um blog comandado por Ramiro Sanchiz que serve de plataforma de difusão de suas ideias sobre a literatura em geral, em especial a uruguaia.

2. Jorge Mario Varlotta Levrero foi um escritor uruguaio, morto em 2004, que trabalhou em seus últimos anos de vida dirigindo uma oficina literária, conseguindo maior reconhecimento por sua obra após sua morte. Hoje, é uma referência chave na literatura uruguaia, em particular para os mais jovens como Sanchiz.

3. A classificação de Lagos (2009), assim como a realizada por Sanchiz (2012), apresentam questionamentos e subdivisões que aqui não nos interessa explorar. Para entender melhor o tema, consulte as referências ao final deste trabalho.

4. Montoya Juárez (2013) afirma que é necessária uma prevenção ante o uso dos termos desterritorializado e reterritorializado, pois quando escritores de determinada nacionalidade criam histórias que se desenvolvem em outros países, há uma desterritorialização e consequente reterritorialização do ambiente mostrado, sendo mais adequado o uso do termo multiterritorialidade.

5. O termo "Suíça da América" foi proposto pela primeira vez por Annatole France, quem afirmou que "En Europe comme en Amérique, vous êtes réputés pour avoir réalisé un type supérieur de civilisation [...] votre situation n'est past sans ressemblance avec celle de la Suisse". (FRANCE apud TRIGO, 1997, p.10).

6. O governo batllista (1903 a 1907 e 1911 a 1915, ainda que seus efeitos tenham se estendido por mais anos), se caracterizou por impulsar a sociedade uruguaia a uma classe média sob a proteção de uma economia pulsante e de um Estado intervencionista que redistribuiu os ganhos entre a população do país.

7. A independência uruguaia aconteceu após um acordo firmado entre Brasil e as Províncias Unidas do Sul, na cidade do Rio de Janeiro, em 1928, no que ficou conhecido como La Convención Preliminar de Paz.

8. Esse Artigas imaginário dialoga em partes com o que diz o historiador Vásquez Franco (2014), quem afirma que Artigas foi um excelente líder rural, semianalfabeto, sem nenhum mérito político ou militar e que se comportava de forma egocêntrica e despótica.

9. Os cantos de Maldoror (1869) foi escrito por Isidore Ducasse e é conhecido como um livro maldito por retratar a história de um arcanjo do mal que comete crimes onde evidencia seu sadismo e perversão.

10. O jogo que já morto propõe Rafael a seu filho para que ele possa dar continuidade à sua biografia artiguista e, como prêmio, receber todos os seus livros, possui muito do gênero policial. Por meio das investigações históricas que seu pai desenvolveu no escritório de sua casa, Federico dá o pontapé inicial não apenas na busca do real motivo que culminou na inesperada morte de seu pai, mas também na investigação sobre a "verdadeira" história 
artiguista e a relação do líder com os assassinatos charruas que continuam acontecendo.

11. Planeta Arreit (1976) é considerado por Dobrinin (2006) o terceiro livro de ficção científica uruguaia, e se diferencia de La vista desde el puente por mostrar-nos uma sociedade utópica por meio de um discurso moralista que toca principalmente em temas econômicos e religiosos. 
ACHUGAR, H. El descontento y la promesa: nueva/joven narrativa uruguaya. Montevidéu: Ed: Trilce, 2008.

BORGES, J.L.; CASARES, B.; OCAMPO, S. Antología de la literatura fantástica. Buenos Aires: Ed: Edhasa-Sudamericana, 1940.

BORGES, J.L. Prólogo a "La invención de Morel". In: MONEGAL, E.R. (Org), Jorge Luis Borges. Ficcionario. Una antologia de sus textos. México: Ed: Tierra Firme, 1997, p.160162.

DELGADO, S. "Otro Artigas Siempre". In: Revista Lento, Montevidéu, n.15, p. 42-46, 2014.

DOBRININ, P. "Historia de la Ciencia Ficción Uruguaya - Segunda Entrega". In: Revista Axxón, Buenos Aires, 12 agosto 2006. Disponível em http://www.axxon.com.ar/. Acesso en 10 julio 2015.

LAGOS, J. G. "Nuevas generaciones de narradores uruguayos". In: Revista Todavía, Argentina, no 22, p.1-3, 2009.

MONTOYA JUÁREZ, J. "Multiterritorialidad imaginada en la última narrativa uruguaya: a propósito de $\mathrm{La}$ vista desde el puente de Ramiro Sanchiz". In: Cuadernos LIRICO, Argentina e Uruguai, nº 8, p.2-14, 2013.

PRIETO, J. "'¡Realmente fantástico!': notas sobre distopia y ciencia-ficción en el Río de la Plata". In: ESTEBAN, A.; MONTOYA JUÁREZ, J. Miradas oblicuas en la narrativa latinoamericana contemporánea. Limites de lo real. Fronteras de lo fantástico. Madri: Iberoamericana, 2009, p.57-76.

SANCHIZ, R. "Mario Levrero: el otro y yo". Revista Axxón. Buenos Aires, agosto 2008. Disponível em http://www.axxon.com.ar/.
Acesso em 15 setembro 2015.

$$
\text { . "Ciencia ficción uruguaya (6 }
$$

puntos para un posible manifiesto)". In: Aparatos de vuelo rasante. Montevideo, 2 outubro 2009. Disponível em http:// http://aparatosdevuelorasante.blogspot.com.

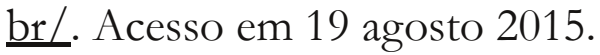

. Ciencia ficción uruguaya. Aparatos de vuelo rasante. Montevideo, 13 outubro 2010. Disponível em http:// http://aparatosdevuelorasante.blogspot.com. br/. Acesso em 19 agosto 2015.

Montevideo: Estuario, 2011.

$$
\text { "Esa rara ciencia ficción }
$$
uruguaya". In: Aparatos de vuelo rasante. Montevideo, 4 maio 2011a. Disponível em http://aparatosdevuelorasante.blogspot.com.

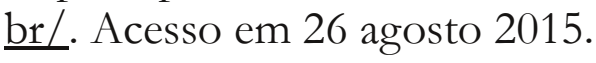

$$
\text { "Una breve historia de la }
$$
ciencia ficción uruguaya". In: Aparatos de vuelo rasante. Montevideo, 14 outubro 2011b. Disponível em $\underline{\text { http:// }}$ http://aparatosdevuelorasante.blogspot.com. $\underline{\mathrm{br} /}$. Acesso em 26 agosto 2015. "El espejismo y la promesa". In: Ya te Conté. Montevideo, 4 dezembro 2012. Disponível em http://www.yateconte.com/. Acesso em 10 maio 2015.

TAGLIAFERRO, G. "Historiador Guillermo Vázquez Franco canta 'Las 40”". In: Montevideo Portal. Montevidéu, 16 de julho de 2013. Disponível em http://www.montevideo.com.uy/. Acesso em 20 junho 2015.

TRIGO, A. ¿Culturas uruguayas o culturas linyeras? Para una cartografía de la neomodernidad posuruguaya. Montevidéu: Ed. Vintén, 1997. 